\title{
Panel criticizes South African advisory councils, priorities
}

Cape Town. South Africa spends too much on nuclear energy and high-energy physics, according to an outside review of government funding of science that was also very critical of the actions of two research advisory councils.

The review, by the International Development Research Centre of Canada, followed the approach taken by the Committee on Science and Technology Policy of the Organization of Economic Cooperation and Development (OECD) and was led by the former chairman of the OECD committee, James Mullin. Mullin was accompanied by Deanna Ashley of the Jamaican Ministry of Health; Thomas Odhiambo, director of the International Centre of Insect Physiology and Ecology in Nairobi; Lydia Makhubu, vice-chancellor of the University of Swaziland; and Geoffrey Oldham, former director of the Science Policy Unit at the University of Sussex.

Responding to an invitation from the African National Congress (ANC), the panel visited South Africa for two weeks last autumn. Its members found themselves unable to judge the value of the Scientific Advisory Council (SAC), which advises the cabinet on the allocation of the science budget, because its recommendations to government are kept confidential. Even so, the SAC was criticized for not having raised questions about the effects of a fiveyear decline of 25 per cent in the purchasing power of grants to the statutory councils after its chairman, Chris Garbers, informed the mission that all the SAC's advice has so far been accepted by the government.

Criticism was also directed at the $\mathrm{Na}$ tional Accelerator Centre (NAC), which is administered by the Foundation for Research Development (FRD), which funds basic academic research. The centre accounts for a quarter of the foundation's annual budget of $\$ 42$ million, although this money is earmarked by the cabinet. The major facility at NAC is a variable energy cyclotron capable of producing $200 \mathrm{MeV}$ protons (see Nature 327, 271; 1987).

One-third of its beam time is allocated to research in nuclear physics, where novel work is limited by the energy range produced by the beam. The remaining beam time is used for neutron and proton therapy for cancer and for medical isotope production. But the review concluded that the medical justifications for "the continued funding of NAC do not withstand scrutiny from any reasonable public health perspective, given the costs involved".

Also under fire is the Atomic Energy Corporation (AEC); its annual state subsidy of $\$ 142$ million compares with the $\$ 238$ million given to the country's six research councils. The AEC's main function is to produce enriched uranium for South Africa's sole nuclear power plant, although it derives some income from non-fuel products as well, and spends about $\$ 25$ million annually on research related to these functions.

The review criticizes the AEC's development as having "ignored entirely any factors relating to the commercial viability of processes being developed". It suggests that the knowledge acquired in the course of the AEC's development be redeployed in non-nuclear industrial activities. The corporation's chief executive, Waldo Stumpf, agrees that the government's support has been generous but points out that the proportion of its budget derived from the state subsidy is expected to decline from twothirds to one-fifth in five years.

The mission aimed its harshest criticism at the Human Sciences Research Council (HSRC), which carries out in-house research. Its usefulness, according to the review panel, is "irretrievably compromised [because of its role] as the source of much of the analysis that lay behind the policy of Grand Apartheid". The panel suggests that government departments could commission socialscience research projects as needed.

The report has been generally well-received by universities, despite some concern about its perceived bias against fundamental research. Although the panel praises fundamental science, which currently receives less than ten per cent of what the government spends on civilian research and development, it suggests that the two major agencies in this area, the FRD and the Medical Research Council, should allocate more of their funds to special and public health programmes respectively. In particular, the mission believes that agricultural research receives too much money and that environmental research should receive much more.

The report urges a prompt and thorough review of the directions of military and space research. While this fell within the mission's terms of reference, Mullin says that it was denied access to relevant information. Although Mullin says that "debate now has to progress from an analysis of present deficiencies to suggestions about possible solutions", the panel decided that the decisions must be left to the scientific community itself.

Michael Cherry

\section{South Africa admits to having six bombs}

Cape Town. The South African president, F.W. de Klerk, ended twenty years of specula tion about the country's nuclear capability when he announced in parliament last week that six nuclear devices had been constructed - but never tested - during the $1980 \mathrm{~s}$. Since South Africa acceded to the Nuclear Non-Proliferation Treaty (NPT) in July 1991 , the devices (which had been constructed by the quasi-governmental armaments corporation ARMSCOR) have been dismantled and the highly enriched uranium inside them has been returned to its source, the Atomic Energy Corporation (AEC).

The AEC will use this material for the commercial production of isotopes at its SAFARI-1 research reactor, built by the United States in 1965 and operating under international safeguards. That is a plausible explanation, given that the reactor was designed to use uranium enriched to 93 per cent, although it has been operating on 45 per cent loads since the United States suspended shipments in 1977.

South Africa's pilot enrichment plant at Valindaba (a word from the African language Sotho, meaning "about this we do not speak"), near Pretoria, became fully operational the following year, and in 1981 it was announced that it had produced 45 per cent reloads for SAFARI-1. However, between 1978 and early 1990, when it was decommissioned (see Nature 347,$417 ; 1990$ ), the pilot plant also produced enough material enriched to weapons grade (usually 93 per cent) to produce seven nuclear devices, six of which had been built by the time de Klerk was elected in September 1989.

Upon assuming office, de Klerk halted production of weapons-grade material and ordered the dismantling of the devices and the return of the enriched uranium to the AEC. The AEC's state subsidy, which peaked at R980 million (US $\$ 310$ million) in $1989-90$, has been reduced by more than half in the past three years and no longer includes expenses associated with enrichment for weapons.

South Africa included the weapons-grade uranium in its inventory submitted to the International Atomic Energy Agency (IAEA), which has carried out more than a hundred inspections since October 1991. The IAEA has been careful to honour its commitment to keep confidential what it has learned, but there is scepticism that South Africa has disclosed all its weapons-grade uranium.

De Klerk emphasized that the bombs were never tested, a claim substantiated by the IAEA's failure to detect evidence of fallout. He claims that the devices, although designed for delivery from an aircraft, were to be used only as a deterrent.

M.C. 